\title{
A psicodinâmica do trabalho nas fases do capitalismo: análise comparativa do taylorismo-fordismo e do toyotismo nos contextos do capitalismo burocrático e do capitalismo flexível
}

\author{
Psychodynamic of the Work in Capitalism phases: \\ Analysis Comparative of Taylorism-Fordism and \\ Toyotism in Contexts to bureaucratic capitalism and \\ Flexible Capitalism
}

\author{
Juliana Carvalho de Sousa ${ }^{1}$ \\ Ana Cristina Batista dos Santos ${ }^{2}$
}

\section{Resumo}

O estudo apresenta os resultados de uma pesquisa sobre a psicodinâmica do trabalho (PDT) nas fases recentes do capitalismo, analisando-se comparativamente o taylorismo-fordismo e o toyotismo nos contextos do capitalismo burocrático e capitalismo flexível respectivamente. Metodologicamente, o estudo foi realizado por meio de uma pesquisa qualitativa do tipo bibliográfica, utilizando-se a técnica da análise temática de conteúdo de maneira similar à análise dos núcleos de sentido (ANS). Os resultados são apresentados a partir do frame teórico da PDT, articulando suas dimensões de contexto (condições de trabalho, organização do trabalho, relações de trabalho) e suas dimensões de conteúdo (carga psíquica, prazer-sofrimento, saúde-adoecimento e estratégias de defesa), em cada um dos modelos de produção-gestão investigados. Conclui-se que a PDT é qualitativamente mais complexa no modelo toyotista (capitalismo flexível), dado o peso da dimensão subjetiva e algumas ilegibilidades do contexto de trabalho atual, do que quando imperava apenas o modelo de produção taylorista/fordista (capitalismo burocrático).

Mestranda em Administração. Afiliação: Universidade Estadual do Ceará (UECE). Brasil. Lattes: http://lattes.cnpq.br/2002557867629902 Email: juli_carvalho18@hotmail.com

2 Doutora em Administração pela Universidade Federal do Rio Grande do Norte (UFRN). Afiliação: Universidade Estadual do Ceará (UECE). Brasil. Lattes: http://lattes.cnpq.br/3198136796795693 Email: ana.batista@uece.br 
Como proposta para estudos futuros tem-se a investigação da PDT em configurações diversas, não necessariamente restritas ao contexto de uma organização formal de trabalho.

Palavras-chave: Psicodinâmica. Capitalismo. Taylorismo. Fordismo. Toyotismo.

\section{Abstract}

The study presents the research's results about psychodynamics of work in the current phases of capitalism, analyzing comparatively taylorism-fordism and toyotism in the contexts of bureaucratic capitalism and flexible capitalism, respectively. Methodologically, the study was accomplished by the way a qualitative research of bibliographical type, using the technique of content thematic analysis of the similar way to the analysis of units of meaning. The results are presented through the theoretical frame of the POW articulating its dimensions of context (working conditions, labor organization, labor relations) and its content dimensions (psychic load, pleasure-suffering, health-illness and defense strategies) in each of the models of production-management investigated. It has concluded that a POW is qualitatively more complex in the toyotist model (flexible capitalism), given the weight of the subjective dimension and some illegibility of the current context of work, than when prevailed just the production model taylorist/fordist (bureaucratic capitalism). As proposal for further studies, has it the investigation of the POW in the several settings not necessarily restricted the context of a formal labor organization.

Keywords: Psychodynamics. Capitalism. Taylorism. Fordism. Toyotism.

\section{Do contexto, objeto e método}

A psicodinâmica do trabalho, doravante PDT, corrente teórica originada e já consolidada na França pelos trabalhos de seu proponente e seus seguidores (DEJOURS, 1992, 1996, 1999; DEJOURS; ABDOUCHELI; JAYET, 1994), e também amplamente difundida e utilizada no Brasil, especialmente pelos campos da Psicologia e Sociologia do trabalho (MARTINS; MENDES, 2012; MERLO; LAPIS, 2007), apresenta-se, progressivamente, como uma lente analítica apropriada também para o campo da Administração, principalmente para os estudos que, nesse território, se ocupam com o exame da relação homem-trabalho (MENDES, 1995). Tal aproximação se justifica, em 
parte, pelo interesse comum, dessas diversas áreas do conhecimento, pelo construto contexto de trabalho.

A PDT, desde a obra seminal de Dejours (1992), defende que o contexto de trabalho deve ser investigado para compreensão da relação homem-trabalho, propondo o exame das seguintes dimensões: i) condições de trabalho; ii) organização do trabalho; e iii) relações de trabalho. A dimensão organização do trabalho engloba desde a divisão do trabalho e o conteúdo de tarefa dela decorrente, a temas como hierarquia, relações de poder, comando e sistemas de responsabilidade. Ambiência física, química e biológica da organização de trabalho, assim como aspectos ligados à higiene e segurança, são temas que qualificam a dimensão condições de trabalho. Quanto às relações de trabalho, consideram-se os laços sociais construídos a partir do contexto da organização de trabalho, seja com chefias e colegas, seja com outros trabalhadores (DEJOURS, 1992; MENDES, 2007).

As condições de trabalho podem ser responsáveis por distúrbios mentais quando se configuram como excesso de trabalho, exigência exacerbada das aptidões do trabalhador, monotonia, etc. Desta forma, tem-se que as condições nas quais o trabalho é realizado podem transformá-lo em agradável/favorável ou em uma experiência penosa e dolorosa, podendo ocasionar o sofrimento do indivíduo (CARRASQUEIRA; BARBARINI, 2010).

Sobre a organização de trabalho, Dejours (1994) esclarece que envolve vários aspectos, dentre eles: o conteúdo das tarefas, as relações de poder entre níveis hierárquicos e as responsabilidades atreladas aos cargos. A relação com o trabalho manifesta-se, assim, como primordialmente social e intersubjetiva. No que diz respeito às relações de trabalho, Dejours (2004) aborda que é a partir do trabalho que o indivíduo cria vínculos sociais, englobando as interações hierárquicas e coletivas, além de relacionar-se com os entes externos, envolvendo os tipos diversos de stakeholders (LAVNCHICHA, 2015).

Segundo a corrente dejouriana, é nesse cenário tridimensional que a PDT - aqui entendida como os "movimentos psicoafetivos, 
pela evolução dos conflitos intersubjetivos e intrasubjetivos", daquele que trabalha (DEJOURS, 1994, p. 18-19) - se manifesta através de dimensões como: carga psíquica, prazer-sofrimento, saúde-doença, estratégias de defesa. A carga psíquica pode resultar do atrito entre o desejo do trabalhador e os objetivos e prescrições da organização, gerando uma permanente tensão entre o trabalho prescrito e o trabalho real, com consequente elevação da carga psíquica. De modo geral, a carga psíquica tende a aumentar quando a liberdade de organização do trabalho diminui (DEJOURS, ABDOUCHELI, JAYET, 1994).

No que diz respeito ao prazer, para Dejours (1992) e Mendes (2007), a vivência dele está atrelado ao reconhecimento e à valorização do indivíduo perante a organização de trabalho. A transformação de situações desfavoráveis na busca do prazer, para Lavnchicha (2015), é o grande objetivo da psicodinâmica. Sobre o processo de saúde e adoecimento, tem-se o ambiente de trabalho como importante fator de efeito na saúde dos trabalhadores, perpassando pelas condições de trabalho, afetando o físico dos indivíduos e envolvendo também os aspectos subjetivos, atrelados ao aparelho psíquico dos trabalhadores (LAVNCHICHA, 2015).

No que tange às estratégias defensivas, estas se organizam através de consenso, unidas a fim de enfrentar o sofrimento causado pelo trabalho, além de minimizar a percepção do sofrimento, protegendo a psique do indivíduo (DEJOURS, ABDOUCHELI, JAYET, 1994). Contudo, é importante ressaltar que o termo estratégia de defesa sofreu uma evolução, passando a ser chamado de estratégias de enfrentamento. As estratégias de enfrentamento (sofrimento criativo) podem se caracterizar como recurso para uma convivência saudável no ambiente de trabalho, no qual o sujeito enfrenta as adversidades a fim de tornar-se satisfeito mediante as atividades que desempenha. Essas estratégias perpassam pelo conformismo, individualismo, negação de perigo, agressividade, passividade, dentre outras (DEJOURS, 1992; SANTOS, 2006).

As bases conceituais da PDT estão, portanto, relacionadas à dinâmica inerente ao contexto de trabalho, que pode tornar-se um local 
impulsor de saúde/prazer e/ou de patologias/adoecimentos (MENDES, 2007). A PDT tem sido usada pelo menos em duas perspectivas, por vezes complementares, por vezes isoladamente: como lente analítica para compreender o trabalho e o trabalhador nos mais diversos contextos de trabalho (BATISTA-DOS-SANTOS et al., 2015; FACH et al., 2009), e/ ou como clínica do trabalho com todas as possibilidades de intervenção e transformação do real que ela possibilita (MARTINS; MENDES, 2012).

Em geral, no Brasil, as publicações em PDT tendem a se originar de pesquisas empíricas sobre os mais diversos contextos de trabalho e trabalhadores (CARVALHO; GARCIA, 2011; FONSECA; MORAES, 2012; GUIMARÃES JÚNIOR; MACEDO, 2013), de ensaios sobre teoria e/ou método em psicodinâmica (MENDES, 2007a, 2007b), ou, ainda, de textos compiladores das práticas de intervenção da clínica do trabalho (GHIZONI et al., 2014). Este texto, por sua vez, se propõe a um resgate histórico comparativo, buscando empreender uma análise das dimensões da PDT em função do contexto econômico (fases do capitalismo recente) e os sistemas de produção-gestão correspondentes. Entende-se que tal resgate contribui para melhor situar o tema, em termos de suas manifestações históricas, e, principalmente, auxiliar na compreensão das mudanças que a própria teoria precisa incorporar para "ler" os fenômenos sempre mutantes do trabalho contemporâneo.

O texto parte, então, da classificação de Boltanski e Chiapello (2009) sobre as fases do capitalismo recente - capitalismo burocrático e capitalismo flexível - e examina a PDT nos sistemas taylorista-fordista (capitalismo burocrático) e toyotista (capitalismo flexível). Desta forma, delimita-se como questão de pesquisa: O que se pode entender sobre a análise das dimensões da PDT em função do contexto econômico (fases do capitalismo recente), e os sistemas de produção-gestão as quais correspondem? Acerca da relevância do trabalho, destaca-se que o presente estudo visa contribuir com a literatura para o desenvolvimento de pesquisas nessa área.

Metodologicamente, foi realizada uma pesquisa qualitativa, do tipo bibliográfica, tendo como "campo" um conjunto limitado de 
vinte e três livros, três artigos publicados em anais de eventos, como o Encontro de Gestão de Pessoas e Relações de Trabalho (EnGPR/ ANPAD) e o Seminário em Administração FEA-USP: Ensino e Pesquisa em Administração (SEMEAD). Além disso, o trabalho baseia-se em dezessete artigos publicados em diferentes periódicos. O critério de inclusão das obras foi sua vinculação temática com os sistemas produtivos e administrativos em análise: taylorismo-fordismo e toyotismo.

A abordagem qualitativa foi utilizada por se objetivar, no desenvolvimento da pesquisa, uma maior explicação sobre o assunto pesquisado, trabalhando com o universo de significados, motivos, aspirações, crenças, valores e atitudes, e atrelando-se a um espaço mais profundo das relações (MINAYO, 2013). Durante a pesquisa, atentou-se principalmente para o universo de significados e crenças prevalecentes em cada período histórico investigado. O material empírico se constituiu, então, da palavra escrita, em linguagem científica, posto que originário da comunidade científica que produz sobre o tema.

A técnica de análise dos dados utilizada foi a análise temática de conteúdo, usada de maneira similar à análise dos núcleos de sentido (ANS) proposta por Mendes (2007b). Bardin (1977) aborda que a análise temática de conteúdo é feita através da análise temática e da análise dos procedimentos. As etapas desse processo são: pré-análise (organização do material, leitura flutuante, preparação do material); exploração do material (realiza-se a categorização, originária dos temas); e o tratamento dos resultados (inferência e interpretação, análise reflexiva e crítica). A leitura e a categorização do material foram realizadas buscando-se identificar os núcleos de sentido do "discurso escrito" sobre cada modelo de produção e gestão.

\section{Das fases recentes do capitalismo e seus modelos de produção e gestão}

Boltanski e Chiapello (2009) entendem que a sobrevivência e continuidade do capitalismo dependem sempre de um ideário, de uma 
ética própria, ou, como eles nomeiam, de um "espírito" que o promova e justifique, como uma espécie de espírito do tempo. Assim, classificam o capitalismo recente em três fases sucessivas ou três espíritos.

O capitalismo familiar corresponde ao primeiro espírito, predominante da passagem do século XIX para o século $X X$, e nas primeiras décadas deste último. Tempos em que propriedade e gestão se confundiam. O burguês empreendedor, capitão de indústria conquistador, tipo característico de uma moral burguesa, era a figura central. Temas como especulação, risco e inovação compunham a pauta da época. Havia uma associação entre, de um lado, disposições econômicas inovadoras, e, de outro, posicionamentos domésticos tradicionais, que, do ponto de vista das relações de trabalho, caracterizavam-se pelo caráter familiar ou patriarcal das relações mantidas com os empregados, "o que será denunciado como paternalismo, cujas formas de subordinação permanecem amplamente pessoais, em firmas geralmente pequenas" (BOLTANSKI; CHIAPELLO, 2009, p. 49-50).

O segundo espírito é o que se expressa no capitalismo burocrático, prevalente na metade do século $X X$, cujos tempos áureos foram do período pós-guerra até a década de 1960, e chegando aos entornos das últimas décadas do século XX. Na década de 1960, em especial, o cenário da organização de trabalho é, por um lado, a proeminência de uma mão de obra gerencial, os administradores profissionais, não proprietários, tipificados pelos executivos (burocratas) das grandes corporações; e, por outro lado, uma grande massa de subordinados ocupando a base de organizações piramidais. É a fase da centralidade da gerência, donde historiadores do management qualificam o capitalismo como gerencial (CHANDLER, 1984).

Ao nível da propriedade e gestão, assiste-se à passagem de uma burguesia patrimonial (capitalismo familiar) para uma burguesia de trabalhadores assalariados (capitalismo burocrático), portadores de diploma superior e integrados a grandes administrações públicas ou privadas, ressaltando-se a proeminência dos administradores, geralmente tipificados pelos executivos ocupantes de postos nos altos 
escalões empresariais dos países de primeiro mundo. Para Chandler (1984), uma característica distintiva dessa fase do capitalismo era exatamente a existência de uma hierarquia de gerentes no contexto da empresa integrada verticalmente. Assim, o cenário da grande empresa era de uma hierarquia composta de numerosos gerentes (planejadores, organizadores, controladores) e de uma igualmente numerosa massa de trabalhadores (executores, controlados).

Pode-se afirmar que o capitalismo burocrático de que tratam Boltanski e Chiapello (2009) corresponde, em termos sociológicos, ao capitalismo monopolista tipificado por Braverman (1987), numa perspectiva mais economicista, ou ao capitalismo gerencial de Chandler (1984), mais focado na realidade organizacional.

É no cenário da passagem do capitalismo familiar para o capitalismo burocrático que o sistema taylorista-fordista emerge e se consolida. Anteriormente à proposta de Taylor (2012), os antigos modelos de produção não delimitavam maneiras de executar a tarefa, cabendo também ao trabalhador a escolha do instrumento de trabalho. $O$ cenário do século XIX era de uniformidade e padronização praticamente nulas para realização de tarefas, sem codificação e análise sistemática para orientação do trabalho (TAYLOR, 2012).

Segundo Taylor (2012), dentre os sistemas de administração vigentes à época, a administração por iniciativa e incentivo era a melhor opção para os dirigentes. Por esse "modelo gerencial", a única forma de conseguir a iniciativa dos trabalhadores era dar-lhes incentivos especiais, como melhoria do ambiente de trabalho, promoção, aumento salarial, dentre outros. Imerso nesse contexto e fortemente influenciado pelo movimento works management ${ }^{1}$, respondendo às demandas da época, Taylor apresenta a administração científica visando implementar o controle sobre o trabalho e trabalhador. Dessa forma, instalou na atmosfera da administração científica a era do homo economicus, indivíduo valorizado a partir da sua produtividade. $\mathrm{O}$ modelo produtivo foi testado e aplicado nos Estados Unidos em meados dos anos 1880, 
porém, só formalizou-se em 1911, por meio da obra Princípios da Administração Científica (MARTINS, 2001; TAYLOR, 2012).

O sistema da administração científica baseia-se em quatro princípios: planejamento, seleção, controle e cooperação. O planejamento refere-se à substituição do critério do operário pelo desenvolvimento de uma ciência que especifica como as tarefas devem ser realizadas. A seleção do trabalhador remete à instrução e treinamento do operário. Devia-se encontrar o biotipo ideal, o "homem do tipo bovino", devendo "[...] exercitá-lo por meio de instrutor competente em novos métodos, até que o trabalho prossiga regularmente, de acordo com as leis científicas, desenvolvidas por outrem [...]" (TAYLOR, 2012, p. 55). O terceiro princípio é o controle, efetivado pela constante supervisão da direção, para que as tarefas sejam desenvolvidas com base nas leis científicas do trabalho, surgindo, assim, a figura do instrutor. O último princípio baseia-se na cooperação, que tem a função de dividir equilibradamente as responsabilidades, na qual "[...] a administração encarrega-se das atribuições para as quais está mais aparelhada e os operários das restantes" (TAYLOR, 2012, p. 84).

O taylorismo enfatiza a tarefa, a sua racionalização, com consequente redução do tempo necessário para desenvolvê-la, e vendo, neste ponto, o da realização da tarefa em menor tempo, uma fonte de eficácia (DURANTE; TEXEIRA, 2008). Com o conhecido estudo de tempos e movimentos, buscavam-se normas e procedimentos sistemáticos a fim de eliminar movimentos desnecessários, determinando o melhor método e tempo para execução (SENNETT, 2002). Desde o ponto de vista estrutural da empresa capitalista de então, associa-se ao taylorismo um padrão de estrutura rígida e hierarquizada (MERLO; LAPIS, 2007).

A partir do estudo dos tempos e movimentos, as atividades foram decompostas em parcelas. Essas tarefas não deviam ser ocupadas por qualquer trabalhador, mas pelo homem certo. Com base nisso, Taylor intitulou a máxima "o homem certo no lugar certo" (MERLO; LAPIS, 2007, p. 63); isto é, aquele trabalhador cujo corpo se ajusta adequadamente 
e de maneira submissa ao sistema científico pensado, e ao que the é prescrito em termos de tarefa. Taylor eliminou a "vadiagem no local de trabalho", vadiagem que anteriormente se traduzia nos momentos em que os trabalhadores produziam em um ritmo menor do que o esperado, sendo então considerados como perda de tempo, de produção e de lucro (DEJOURS, 1998).

Durante mais da metade do século $X X$, os modelos de produção que se difundiram por diversos países industrializados foram baseados nos princípios da administração científica e na organização racional do trabalho, junto às inovações introduzidas por Henry Ford (FARIA; KREMER, 2004). Ford propunha um modelo de produção que implementava a administração científica do trabalho em suas fábricas e conseguiu acelerar a produção, reduzindo os custos dos veículos fabricados pela Ford Motor Company. Este fato foi um marco para as fábricas de Highland Park, em Detroit, onde foi introduzida, em 1913, a linha de montagem móvel e o complexo de Rouge, implementando um modelo de produção padronizado e verticalizado, conhecido como modelo de produção fordista (MAROCHI, 2002; MARTINS, 2001).

O fordismo configurou-se como um aperfeiçoamento do taylorismo, podendo ser caracterizado como extensão da administração científica. Facas (2009) entende que a principal contribuição do fordismo para o crescimento das grandes empresas próprias ao capitalismo burocrático foi o mecanismo do trabalho repetitivo, garantido pela implementação da esteira mecânica com o intuito de intensificar a produção (TRINDADE, 2004).

Em síntese, o taylorismo-fordismo emergiu e se consolidou nos tempos do segundo espírito do capitalismo, o burocrático, a partir de vários conceitos estruturantes: divisão do trabalho, racionalização do trabalho, cisão entre planejamento e execução do trabalho, sequências lineares de trabalho, operações fragmentadas, linha de montagem, equipamentos especializados, porém, pouco flexíveis, trabalho prescrito pela gerência, ausência de autonomia do trabalhador, dentre outras (TRINDADE, 2004). 
Quanto ao atual espírito do capitalismo, Boltanski e Chiapello (2009) o apresentam como um novo espírito, o flexível, potencializado a partir das últimas décadas do século $X X$. Este novo espírito corresponde à fase de acumulação flexível do capital, ou regime de acumulação flexível (BOLTANSKI; CHIAPELLO, 2009; FARIA; KREMER, 2004; GURGEL, 2003; MENDES, 2007b), que, pelo menos discursivamente, é apresentado como promotor de mudanças radicais em três dimensões do mundo do trabalho: (i) a produção; (ii) as organizações de trabalho; e (iii) a gestão. Os anos 1990 se tornam decisivos na busca por uma flexibilização da burocracia, em que se destaca o discurso da luta antiburocrática.

A contemporaneidade vem sendo, então, descrita como tempo de intensas e rápidas mudanças, de processos de rupturas, descontinuidades e incertezas. Passa-se a uma "normalização da mudança pela perpetuação de tudo como volátil e transitório" (VIEIRA; CALDAS, 2006, p. 6), ou líquido, como qualifica Bauman(2001). Importantes transformações podem ser percebidas nas diversas esferas da vida humana associada, dentre as quais, destacam-se: as revoluções tecnológicas; a mundialização do capital (CHESNAIS, 1996); a elevação da competitividade entre os agentes econômicos com correspondente proeminência de uma sociedade do consumo; novas formas de relações entre as pessoas, que parecem derivar para um processo de transmutação da identidade; além de variadas maneiras inovadoras de relações organizacionais e institucionais (CLEGG; HARDY, 1998; CHESNAIS, 1996; FONTENELLE, 2008; GURGEL, 2003; MENDES, 2007b; SENNETT, 2007, 2006; VIEIRA; CALDAS, 2006).

Quanto ao contexto interno da empresa capitalista, o toyotismo desponta, a partir das últimas décadas do século $\mathrm{XX}$, como nomenclatura que abarca o sentido das novas formas de produção e gestão das empresas imersas nesse terceiro espírito do capitalismo, o flexível. Sistema originado no pós-guerra japonês, no movimento de reconstrução de sua indústria nacional, o toyotismo surge, no entorno da década de 1980, como modelo apropriado também para a reestruturação produtiva no ocidente capitalista. Tem como principal característica a produção 
flexível e os investimentos em tecnologias de base microeletrônica com grupos heterogêneos, que buscam redução de estoque, induzindo a um processo de terceirização do trabalho por parte das empresas capitalistas centrais (FARIA; KREMER, 2004; FLACH et al, 2007).

A mudança no modelo de produção toyotista foi iniciada pelo engenheiro Taichi Ohno, o qual desenvolveu máquinas que permitiam maior flexibilidade na manipulação das ferramentas. A partir disso, constatou que, quando se produzia pequenos lotes, os custos atrelados à produção eram menores (MAROCHI, 2002). Na década de 70, o toyotismo passa pela primeira fase, caracterizada principalmente pela implementação dos Círculos de Controle de Qualidade (CCQ's). A segunda fase do processo, ocorrido a partir da metade dos anos 80, envolve a implementação do Just in time e do Kanban; além disso, há a implementação do Controle Estatístico do Processo (CEP) e dos programas de qualidade total (FARIA; KREMER, 2014). Ohno (1997, p. 25) defende que "os dois pilares necessários à sustentação do sistema são: Just in time e autonomação, ou automação com um toque humano". O primeiro conceito refere-se ao momento certo em que os objetos necessários chegam à linha de produção em quantidades corretas. $\mathrm{E}$ o segundo conceito remete-se ao envolvimento do capital intelectual do homem com a máquina.

Merlo e Lapis (2007) abordam que essas técnicas apresentadas ao Ocidente possuem como objetivos principais a elevação na produtividade, redução nos custos, além da promoção de um controle preciso na qualidade. Com relação à redução nos custos de produção, também conhecido como Kaizen (melhoria contínua), pode-se afirmar que é um dos principais objetivos do sistema de produção Toyota. Essa redução envolve a busca pela economia na mão de obra, extinguindo todos os intervalos no processo produtivo e investindo no aumento do ritmo máximo de trabalho. É importante destacar a aceitabilidade por parte dos trabalhadores, devido às remunerações serem diretamente atreladas à redução de mão de obra (BOLTANSKI; CHIAPELLO, 2009). 
Desta forma, tem-se que os principais objetivos que configuram o Sistema Toyota de Produção envolvem a eliminação de desperdícios visando ganhos de produtividade, a qual é obtida também por se "produzir muitos modelos em pequenas quantidades". A produção em pequenas séries de variedade cada vez maior envolve a preocupação em aproximar-se dos desejos dos consumidores. Esse fato é o que irá caracterizar a passagem da produção em massa para a "produção flexível” (BOLTANSKI; CHIAPELLO, 2009, p. 132). Há uma necessidade de pôr mais produtos no mercado, com uma maior rapidez (SENNETT, 2002). A partir de então, as empresas passaram a superar a rigidez advinda do modelo taylorista-fordista e a dispersar-se geograficamente para novos nichos mercadológicos (MERLO; LAPIS, 2007).

Polivalência e rotatividade de operações são formas adotadas para garantir a continuidade no ritmo do processo produtivo (MERLO; LAPIS, 2007). Ao supervisor, cabe o "esforço para transformar a movimentação dos operários em trabalho" (OHNO, 1997, p. 24). Sobre a dimensão organização do trabalho, o sistema Toyota possui como principais pontos a eliminação rígida das tarefas, contudo, exigia-se um longo treinamento a fim de aperfeiçoar o indivíduo nas funções (multivariedade de funções), a valorização da experiência do trabalhador, a eliminação da especialização nas tarefas, uma organização horizontal, o trabalho em grupo, o envolvimento do trabalhador com os objetivos da empresa, a eliminação dos níveis hierárquicos, a não distinção entre executivos e não executivos, e gestão participativa (BOLTANSKI; CHIAPELLO, 2009; FLACH et al., 2007; MAROCHI, 2002; MERLO; LAPIS, 2007).

Esta é a era das organizações flexíveis, em que impera o "flexitempo", pelo qual os turnos fixos são substituídos por pessoas trabalhando em horários distintos (SENNETT, 2002, p. 66). Boltanski e Chiapello (2009) abordam que um dos motivos para que se adotem organizações flexíveis é a concorrência acirrada, como forma de serem sempre adeptas às transformações, e com mão-de-obra intelectualmente instruída, na qual essa força de trabalho não possa tornar-se improdutiva e facilmente descartável. 
No que tange às qualificações necessárias para uma organização flexível, tem-se as aptidões portáteis, que envolvem o saber ouvir e ajudar o próximo, estando sempre aberto a novas experiências (SENNETT, 2002). Exige-se que haja uma gestão realista pautada nas mudanças constantes e no ambiente de negócio turbulento (OHNO, 1997). O modelo Toyota demanda trabalhadores mais escolarizados, com raciocínio lógico e capacidade de relacionamento interpessoal, sempre motivado e engajado com os objetivos da organização. $O$ controle rígido é substituído por líderes motivadores (MERLO; LAPIS, 2007). Como diz Ohno (1997, p. 88), "o Sistema Toyota de Produção representa uma revolução no pensamento. Porque ele exige que mudemos, fundamentalmente, nossa maneira de pensar".

As diversas nomenclaturas para qualificar o espírito do tempo, no mundo do trabalho atual, a chamada "era da flexibilidade" (reestruturação flexível, produção flexível, organização flexível, gestão flexível, etc.) apresentam um cenário em que várias dimensões do contexto de trabalho, e da vida como um todo, tendem a ser influenciadas por essa nova lógica ou novo paradigma: o da flexibilidade. Ao nível do trabalhador individual, fala-se, por exemplo, de flexitempo (SENNETT, 2007), em que suas experiências laborais passam a se afastar do antigo padrão burocrático (de um corpo inscrito num tempo e espaço padronizados e rotineiros), para se aproximar de uma nova "rotina", caracterizada por um corpo circulante entre lugares e não-lugares (AUGĖ, 1994), transitando entre espaços físicos e virtuais, num mosaico de horários intensos e despadronizados.

Em face desses cenários discursivamente conflitantes, o "mundo real" de trabalho, na contemporaneidade, tende a se apresentar como um grande amálgama do velho com o novo, em que, por vezes, se torna difícil discernir o que se mantém do capitalismo burocrático e seu correspondente "sistema produtivo-organizacional-gerencial" tayloristafordista; o que já se consolidou do capitalismo flexível e o chamado modelo toyotista; e, mais ainda, o que extrapola a esses dois modelos. 


\section{A PDT no modelo taylorista/fordista}

A forma como ocorreu a introdução do taylorismo e também a implementação da linha de montagem fordista sempre foi alvo de debates entre os historiadores do trabalho, pois não é fácil avaliar a dimensão desse modelo produtivo, que afetou as organizações de maneira desigual (BOLTANSKI; CHIAPELLO, 2009) e também as vivências operárias de maneira particularizada. Para Dejours (1992), não há uma "vivência operária que seria um denominador comum a todas as situações de trabalho" (DEJOURS, 1992, p. 12).

Merlo e Lapis (2007) enfatizam que a percepção de que o trabalho tem consequência sobre a saúde dos indivíduos já é antiga. De fato, Dejours (2014) situa os primórdios do interesse pelo tema no que chama de "pré-história da saúde dos trabalhadores", situando no século XIX um foco restrito à dimensão da redução da jornada de trabalho da classe operária. Após um século marcado por lutas operárias com essa pauta, "só a partir do fim do século são obtidas leis sociais pertinentes, especificamente, à saúde dos trabalhadores (DEJOURS, 1992, p. 17)”.

Já no contexto do taylorismo, dominante em boa parte do século XX, a pauta da saúde do trabalho inicia centrada na proteção do corpo para depois evoluir para a saúde mental, pois, como afirma Dejours (1992, p. 18-19), o taylorismo se tratava de uma

Nova tecnologia de submissão, de disciplina do corpo, a organização científica do trabalho gera exigências fisiológicas até então desconhecidas, especialmente as exigências de tempo e ritmo de trabalho. As performances exigidas são absolutamente novas, e fazem com que o corpo apareça como principal ponto de impacto dos prejuízos do trabalho.

Dentre as principais fontes de sofrimento no trabalho estaria, portanto, a rigidez inerente ao taylorismo. Dejours (1992) entende que a organização científica do trabalho gera exigências de tempo e ritmo de trabalho que podem trazer prejuízos para o corpo. Esse esgotamento 
físico não é próprio apenas dos trabalhadores braçais, estendendose a todos os operários da produção em massa por ambos terem sido privados do seu principal protetor: o aparelho mental. Neste sentido, desde sua obra seminal da PDT, Dejours (1992) aponta para a relação de dependência entre corpo e aparelho psíquico. Ele localiza a fonte do possível sofrimento psíquico do trabalhador na neutralização da atividade mental do operário que, no taylorismo, é promovida pela separação radical entre trabalho intelectual e trabalho manual. Ele estabelece uma espécie de sequenciamento na evidência dos prejuízos do taylorismo sobre o trabalhador:

Não é o aparelho psíquico que aparece como primeira vitima do sistema, mas, sobretudo. o corpo dócil e disciplinado, entregue, sem obstáculos, à injunção da organização do trabalho, ao engenheiro de produção e à direção hierarquizada do comando. Corpo sem defesa, corpo explorado, corpo fragilizado pela privação de seu protetor natural, que é o aparelho mental. Corpo doente, portanto, ou que corre o risco de tornar-se doente (DEJOURS, 1992, p. 19).

$\mathrm{Na}$ esteira dessa relação corpo-psiquismo, diversos autores evidenciam os problemas do taylorismo quanto à saúde do trabalhador. Flash et al. (2009) afirmam que a rotinização e repetição das tarefas próprias ao taylorismo podem ser condicionadoras do sofrimento psíquico, podendo elevar-se a lesões advindas dos esforços repetitivos. Merlo e Lapis (2007) abordam que a principal crítica ao taylorismo remete ao impedimento da conquista da identidade no trabalho, ocorrendo nos espaços de tempo do trabalho prescrito e do trabalho real. Ramos (2009) aborda como crítica o fato do taylorismo prender-se em excesso ao objetivo do rendimento máximo do trabalho. Para Dejours (1992), o sistema taylorista favorece o círculo vicioso da alienação, no qual o comportamento dos trabalhadores torna-se condicionado ao tempo, formando uma síndrome psicopatológica. 
Durante e Teixeira (2008) abordam que o indivíduo no trabalho é um ser global, possuidor de necessidades, expectativas, interesses, e precisa desenvolver-se nos aspectos afetivo, psicológico, físico e cognitivo. Ao se tratar os indivíduos como atores previsíveis e passíveis de controle, suas particularidades são desconsideradas. Desta forma, esse modelo de gestão atrelado ao taylorismo aliena o trabalhador ao mesmo tempo em que se impõe e explora.

Com relação à fragmentação da tarefa, essa poderá conduzir para dois sofrimentos específicos: o medo e a monotonia. No que tange à monotonia, ela ocorre pelo intenso ritmo de trabalho, tarefas parceladas, rotina burocrática, controle e movimentos repetitivos. Já com relação ao medo, ele é encarado por dimensões. Uma das dimensões relaciona-se ao desgaste mental e equilíbrio psicoafetivo; outra dimensão aborda o medo específico que se relaciona à desorganização do funcionamento mental, causado pela autorrepressão e pelo esforço para conduzir comportamentos de forma condicionada; por fim, tem-se a dimensão que se refere à deterioração física (MERLO; LAPIS, 2007).

Os operários estão sujeitos a desenvolverem a despersonalização do trabalho, trazendo consequências para a saúde física e mental, podendo ocasionar esgotamentos e fadigas físicas, tensão, angústia, medo, frustração, úlceras e gastrites nervosas, finalizando com o processo de isolamento do indivíduo (MAROCHI, 2002).

De acordo com Dejours (1992, p. 39),

[...] o homem no trabalho, artesão, desapareceu para dar à luz a um aborto; um corpo instrumentalizado - operário de massa - despossuído de seu equipamento intelectual e de seu aparelho mental.

Segundo o autor, diante do cenário de desapropriação do saberfazer, de desmantelo da coletividade operária e quebra da organização trabalhista, o modelo taylorista forma-se apenas de indivíduos isolados e sem iniciativa, podendo ser forte impulsionador do sofrimento no trabalho. Além desses aspectos, Dejours (1992) cita que o sofrimento, 
além de ter relação direta com a mecanização, robotização, pressões e imposições, é causado também pela sensação de incompetência do indivíduo, pela qual o trabalhador sente-se incapaz de enfrentar determinadas situações.

Por outro lado, Dejours (1992) também alerta que situações de trabalho repetitivo, com alta carga psíquica, devido à forte pressão e supervisão exercidas sobre o trabalhador, como é o exemplo do trabalho das telefonistas "taylorizadas" por ele narrado, tende a mostrar que há situações em que os trabalhadores produzem formas específicas de enfrentamento que fazem elevar a produtividade pela mobilização subjetiva do sofrimento. Para diminuir o tempo dos incômodos e irritações durante as ligações, elas tendiam a atender cada vez mais rápido, donde ele afirmava sobre essas empregadas taylorizadas que "é o sofrimento que produz o trabalho" (DEJOURS, 1992, p. 103).

Sobre o prazer atrelado ao ambiente de trabalho, Dejours (1992) diz que o comportamento livre pode ser responsável pela orientação na direção do prazer. Desta forma, o operário em massa pode ter como fonte de prazer esse comportamento que é cedido dentro dos limites de uma organização autoritária do trabalho.

O quadro 1 apresenta os resultados identificados no cruzamento das dimensões de contexto com as dimensões de conteúdo da psicodinâmica do trabalho, no modelo taylorista-fordista, na literatura consultada. 
Quadro 1 - Síntese das dimensões da PDT no sistema taylorista-fordista

\begin{tabular}{|c|c|c|c|}
\hline $\begin{array}{l}\text { Dimensões de } \\
\text { contexto } \rightarrow \\
\text { Dimensões de } \\
\text { conteúdo } \\
\downarrow\end{array}$ & $\begin{array}{l}\text { Condições } \\
\text { de trabalho }\end{array}$ & $\begin{array}{c}\text { Organização } \\
\text { do trabalho }\end{array}$ & $\begin{array}{l}\text { Relações } \\
\text { de trabalho }\end{array}$ \\
\hline Carga psíquica & & $\begin{array}{c}\text { Tensão } \\
\text { Angústia }\end{array}$ & $\begin{array}{l}\text { Pressões } \\
\text { Imposições }\end{array}$ \\
\hline $\begin{array}{c}\text { Prazer- } \\
\text { sofrimento }\end{array}$ & & $\begin{array}{c}\text { Prazer: } \\
\text { Comportamento livre autorizado } \\
\text { Conteúdo significativo da tarefa } \\
\text { Sofrimento: } \\
\text { Falta de identidade } \\
\text { Alienação } \\
\text { Medo } \\
\text { Monotonia } \\
\text { Frustração } \\
\text { Sensação de incompetência }\end{array}$ & \\
\hline $\begin{array}{c}\text { Saúde- } \\
\text { adoecimento }\end{array}$ & $\begin{array}{c}\text { Condições } \\
\text { físicas precárias } \\
\text { de trabalho }\end{array}$ & $\begin{array}{l}\text { Fadiga física } \\
\text { Lesões por esforço repetitivo } \\
\text { Deterioração física (úlceras, } \\
\text { gastrites) } \\
\text { Esgotamento mental }\end{array}$ & \\
\hline $\begin{array}{c}\text { Estratégias de } \\
\text { defesa }\end{array}$ & & Aumento da produtividade & Isolamento \\
\hline
\end{tabular}

Fonte: Elaboração própria (2016).

\section{A PDT no modelo toyotista}

Quanto ao contexto do capitalismo flexível, Flach et al. (2009) elencam fatores indutores do sofrimento no trabalho dentro do contexto da globalização, tais como: exigência por maior qualificação, competitividade, diminuição dos locais de trabalho, etc. Bouyer (2010) aborda que as novas patologias do mundo contemporâneo envolvem a imaterialidade do trabalho, sendo predominantemente de forma subjetiva. $\mathrm{O}$ autor aborda que as atividades do mundo contemporâneo afetam a saúde mental dos trabalhadores por determinados fatos, tais como: a dificuldade em utilizar recursos para a sublimação (defesa) e a falta de reconhecimento. 
A PDT prega a relação entre o funcionamento psíquico e a rigidez do controle, e enfatiza que, quando o segundo termo se exacerba, pode comprometer a saúde do trabalhador. Mas como o controle tem se manifestado nos novos modelos, nos novos tempos, se são tempos em que se fala de empoderamento e autogestão do trabalhador?

Para autores como Bouyer (2010), o que está havendo é uma "retaylorização" de aspectos que envolvem o trabalho, contudo, sob disfarces de sistemas modernos e automatizados. Essa volta atualizada do taylorismo envolve tempos, movimentos, cadências e gestos do trabalho aplicados aos diferentes tipos de serviços, especialmente aqueles mediados pela tecnologia da informação. Para Batista-dosSantos et al (2015), as organizações flexíveis estruturadas em sistemas integrados de gestão, na verdade, tipificam uma atualização sofisticada da forma burocrática de organização na contemporaneidade, em que se evidencia que

trabalhadores envolvidos em processos de implantação tecnológica, ao estilo sistemas ERP, tendem a se envolver em contextos de elevada carga psíquica, com vivências alternantes de prazer-sofrimento mediados por estratégias de defesa que, nesse grupo pesquisado, foram: de racionalização, de negação e hiperatividade. A desistência emergiu como estratégia limite frente ao risco de sofrimento patogênico e adoecimento (BATISTADOS-SANTOS et al, 2015, p. 1).

Bernardo (2009), em estudo empírico com trabalhadores de empresas regidas pelo sistema japonês, discorre sobre resultados da análise do discurso obtido em entrevistas. A autora aborda que expressões como assédio moral, pressão psicológica e humilhações foram termos recorrentes. Há excesso de responsabilidade e apreensão relativa à "humilhação", além do excesso do ritmo de trabalho e sentimento de desvalorização enquanto profissionais. Apesar de haver redução do número de operações que compõem os processos, a redução do tempo para executar as atividades totais é desproporcional. Para as organizações, há uma busca pela superação das metas de produção. 
Além dessas imposições, há ameaças acerca de demissões. Pode-se dizer que se vivencia uma "escravidão oculta".

Expressões como ritmo frenético, trabalho incessante, loucura, desespero, estresse e depressão foram utilizadas pelos trabalhadores para caracterizar o ambiente de trabalho. "As organizações flexíveis estabelecem relações de trabalho bem perversas, pois, na medida em que estão impregnadas de contradição, mantêm os trabalhadores em um estado de inquietude permanente que os expõe a um sofrimento psíquico real" (BERNARDO, 2009, p. 151). Sob as lentes da PDT, o sofrimento daqueles que estão submetidos a essas condições de trabalho, próprias ao modelo japonês, assume novas formas inquietantes que evocam o medo (BERNARDO, 2009).

Merlo e Lapis (2007) trazem abordagens, como individualismo e competitividade, que são consequências do novo espírito do capitalismo, que estaria, por conseguinte, causando o desaparecimento de carreiras estáveis e duradouras, o que, para Sennett (2002), acarreta no risco da corrosão do caráter do indivíduo pela impossibilidade de estabelecimento de vínculos duradouros.

A psicodinâmica envolve ainda o prazer no trabalho e, relacionando a isso, o toyotismo aborda a diminuição de acidentes de trabalho, ambientes laborais mais bem estruturados no que tange à higiene, iluminação e espaço, nos quais o trabalhador braçal é substituído por indivíduos uniformizados. De fato, o medo de acidentes tornou-se relativamente retórico. Contudo, hoje, o sofrimento acontece na psique. Há o medo pela incompetência, medo de não obedecer às imposições, ao ritmo, ao desempenho esperado, aos conhecimentos mínimos exigidos, às instruções exigidas, e de não ter habilidade das relações interpessoais. Hoje há uma competição entre os próprios funcionários, ou seja, há um individualismo exacerbado. A falta de reconhecimento é um fator preponderantemente responsável pelo sofrimento no trabalho. Há ainda o binômio sofrimento-defesa, em que o mecanismo de defesa é desenvolvido nos indivíduos como forma de proteção, transformando o sofrimento em normalidade, tornando-o mais tolerante (FARIA, 1992). 
Flach et al (2009) também explanam que o ambiente de trabalho melhorou estruturalmente, pois os indivíduos ganharam mais autonomia, e a capacidade de pensar e tomar decisões passou a ser mais explorada. Entretanto, os autores destacam que, dentro desse contexto atual, é necessário que se enfrentem alguns desafios, como tempo, talento e abrir mão. O quesito tempo refere-se àquele necessário para manter uma vida profissional e pessoal em equilíbrio. $O$ talento aborda o fato de desenvolver novas capacidades. O abrir mão, por sua vez, envolve permitir que o passado fique para trás, referindo-se ao desapego. Hoje, o sofrimento é mais qualitativamente complexo e sutil do ponto de vista psíquico.

Para Dejours (1992), há na polivalência uma desqualificação com relação às preocupações trabalhistas para encobrir formas de exploração, ou seja, o indivíduo esconde a exploração que the é dada pela aprendizagem de novas tarefas e aumento de atividades delegadas. No contexto atual, o sentido do trabalho tornou-se ilegível, e este aspecto emocional faz com que os trabalhadores não saibam sua direção. Contudo, no quesito operacional, as demandas parecem ser bastante claras (SENNETT, 2002).

Sobre o prazer existente nesse modelo de produção, Dejours (1998) aborda que só haverá prazer diante da aplicação das aptidões físicas e psicossensoriais se existir uma relação entre o prazer e o conteúdo significativo da tarefa. Mendes (1995) afirma que o prazer está atrelado à satisfação de necessidades que são representadas pelos sujeitos. Há uma possibilidade do trabalhador transformar o sofrimento não suportado em criatividade, ou seja, em prazer. Além desses aspectos, o trabalhador pode utilizar a inteligência operária e o processo de reconhecimento simbólico como formas de transformar o sofrimento em prazer no ambiente de trabalho.

O quadro 2 sintetiza os conteúdos identificados na literatura consultada sobre as dimensões da psicodinâmica do trabalho no sistema toyotista. 
Quadro 2 - Síntese das dimensões da PDT no sistema toyotista

\begin{tabular}{|c|c|c|c|}
\hline $\begin{array}{c}\text { Dimensões de } \\
\text { contexto } \rightarrow \\
\text { Dimensões de } \\
\text { conteúdo } \\
\downarrow\end{array}$ & $\begin{array}{l}\text { Condições } \\
\text { de trabalho }\end{array}$ & $\begin{array}{l}\text { Organização } \\
\text { do trabalho }\end{array}$ & $\begin{array}{l}\text { Relações } \\
\text { de trabalho }\end{array}$ \\
\hline Carga psíquica & & Pressão subjetiva & \\
\hline $\begin{array}{l}\text { Prazer- } \\
\text { sofrimento }\end{array}$ & $\begin{array}{l}\text { Flexibilidade na } \\
\text { manipulação } \\
\text { das ferramentas }\end{array}$ & $\begin{array}{c}\text { Prazer: } \\
\text { Mais autonomia } \\
\text { Possibilidade do trabalho } \\
\text { intelectual } \\
\text { Tomada de decisões } \\
\text { Sofrimento: } \\
\text { Assédio Moral } \\
\text { Humilhação } \\
\text { Medo da incompetência } \\
\text { Medo do desempenho } \\
\text { insatisfatório } \\
\text { Aumento de atividades }\end{array}$ & $\begin{array}{c}\text { Prazer: } \\
\text { Reconhecimento } \\
\text { simbólico } \\
\text { Eliminação dos } \\
\text { níveis hierárquicos } \\
\text { Sofrimento: } \\
\text { Falta de } \\
\text { reconhecimento } \\
\text { Medo de não } \\
\text { ter habilidades } \\
\text { nas relações } \\
\text { interpessoais }\end{array}$ \\
\hline $\begin{array}{c}\text { Saúde- } \\
\text { adoecimento }\end{array}$ & $\begin{array}{c}\text { Saúde: } \\
\text { Diminuição de } \\
\text { acidentes } \\
\text { Melhores } \\
\text { condições de } \\
\text { higiene } \\
\text { Adoecimento: } \\
\text { Depressão } \\
\text { Estresse }\end{array}$ & $\begin{array}{c}\text { Intensificação do tempo de } \\
\text { trabalho }\end{array}$ & $\begin{array}{l}\text { Corrosão do } \\
\text { caráter (ausência } \\
\text { de relações } \\
\text { duradouras) }\end{array}$ \\
\hline $\begin{array}{l}\text { Estratégias de } \\
\text { defesa }\end{array}$ & & $\begin{array}{l}\text { Racionalização } \\
\text { Negação } \\
\text { Hiperatividade }\end{array}$ & $\begin{array}{c}\text { Individualismo } \\
\text { Competitividade } \\
\text { Desqualificação } \\
\text { das questões } \\
\text { trabalhistas }\end{array}$ \\
\hline
\end{tabular}

Fonte: Elaboração própria (2016).

\section{Discussão e síntese provisória}

Levando-se em consideração o objeto inicialmente proposto, que consistia em estudar a psicodinâmica do trabalho nas fases do capitalismo, analisando-se comparativamente o taylorismo-fordismo e o toyotismo nos contextos do capitalismo burocrático e do capitalismo 
flexível, tem-se que a pesquisa alcançou seu objetivo por meio das análises de conteúdo realizadas.

No contexto do modelo de produção taylorista-fordista, a PDT mostra-se presente nas diferentes dimensões do trabalho. Na dimensão organização do trabalho, há uma carga psíquica de tensão e angústia. No que tange o prazer, tem-se o comportamento livre autorizado do trabalhador e o conteúdo significativo da tarefa. Quanto ao sofrimento, envolve a falta de identidade, a alienação, o medo, a monotonia, a frustação e a sensação de incompetência. Com relação à saúdeadoecimento, poderá ocorrer desenvolvimento de fadiga física, lesões por esforços repetitivos, deterioração física, como úlceras e gastrites, e esgotamento mental. Quanto às estratégias de defesa, emerge o aumento da produtividade por parte dos trabalhadores. Na dimensão condições do trabalho, a dimensão de conteúdo da PDT que possui associação é a saúde-adoecimento, devido às condições físicas precárias de trabalho que são oferecidas aos indivíduos. E sobre as relações de trabalho, a carga psíquica mostra-se como um dos pontos que podem ser afetados, mediante pressões e imposições. A estratégia de defesa pode se manifestar nessa dimensão do trabalho através do isolamento do indivíduo.

Já no modelo de produção toyotista, o sofrimento baseia-se principalmente na psique. Na dimensão condições de trabalho, as dimensões de conteúdo que enfatizam envolvimento são o prazersofrimento baseando-se na flexibilidade da manipulação das ferramentas. A dimensão de saúde-adoecimento poderá gerar diminuição de acidentes e melhores condições de higiene, contudo, poderá causar também depressão e estresse.

Sobre a dimensão organização do trabalho, a carga-psíquica poderá ser afetada por meio das pressões subjetivas que podem haver dentro das organizações. Com relação à manifestação de prazer, essa poderá ocorrer mediante a autonomia dada ao trabalhador com a possibilidade de trabalho intelectual e tomada de decisões. No que tange ao sofrimento, tem-se o medo pela incompetência e pelo desempenho 
insatisfatório, assédio moral, humilhação, além do aumento do número de atividades que são delegadas aos trabalhadores. Na dimensão de conteúdo saúde-adoecimento, a organização do trabalho impõe a intensificação do tempo de trabalho. Com relação às estratégias de defesa, tem-se a racionalização, a negação e a hiperatividade do indivíduo.

A dimensão relações de trabalho enfatiza associação com o conteúdo prazer, quando os trabalhadores podem alcançá-lo através do reconhecimento que lhes é dado e da eliminação dos níveis hierárquicos, possibilitando uma comunicação entre os chefes e subordinados. Por outro lado, essa dimensão também se relaciona com o sofrimento que poderá haver no ambiente de trabalho com a falta de reconhecimento e medo de não possuir habilidades nas relações interpessoais. Sobre a saúde-adoecimento, tem-se a corrosão do caráter, tão difundida por Sennett (2002), que significa a ausência de estabelecimento de relações duradouras. E com relação às estratégias de defesa, tem-se o individualismo, a competitividade gerada entre os membros e a crescente desqualificação das questões trabalhistas.

Em resumo, quanto ao toyotismo, pode-se afirmar que a PDT é qualitativamente mais complexa do que quando imperava apenas o modelo de produção taylorista/fordista, dado o peso da dimensão subjetiva e algumas ilegibilidades do contexto de trabalho.

O texto possui como limitações o escopo da pesquisa, por se tratar de um estudo apenas bibliográfico. Contudo, o trabalho apresenta contribuições para o avanço e o aprofundamento do arcabouço teórico da PDT ao considerar analiticamente o contexto histórico e econômico mais amplo (fases do capitalismo) e suas manifestações específicas no contexto organizacional (modelos produtivos e de gestão). O texto contribui ainda para fundamentar estudos empíricos sobre a PDT no multifacetado mundo do trabalho contemporâneo, que se traduz como um grande amálgama de burocracia e flexibilidade, de "taylorismofordismo" e "toyotismo". 
Como proposta para estudos futuros, tem-se: a investigação da PDT em configurações diversas de trabalho, não necessariamente restritas ao contexto de uma organização formal de trabalho. Assim, sugere-se pesquisar sobre a PDT associada ao empreendedorismo individual, às novas formas de carreira, ao desenvolvimento do trabalho em contextos domésticos e/ou virtual. Tal exame certamente possibilitará, a partir da empiria, a atualização das dimensões teóricas de contexto e de conteúdo da PDT.

\section{Notas:}

1 O taylorismo foi antecedido pelo movimento conhecido como works management, o qual se institucionalizou por meio de mudanças específicas dentro das associações profissionais de engenharia em face da demanda de qualificação da mão de obra, após a Guerra de Secessão norte-americana. Uma série de jornais ingleses e norte-americanos da área de engenharia difundiram as novas ideias, de racionalização, organização e controle do trabalho, do works management.

2 O conceito de "não-lugar", em Augè (1994), se refere a espaços como avenidas, rodovias, aeroportos, hotéis, shoppings, redes de fast-food, caixas eletrônicos etc. Ele afirma: "se um lugar pode se definir como identitário, relacional e histórico, um espaço que não pode se definir nem como identitário, relacional e histórico, definirá um não-lugar" (AUGÈ, 1994, p. 73).

\section{Referências}

AUGĖ, M. Não-lugares: introdução a uma antropologia da supermodernidade. 7 ed. Campinas, SP: Papirus, 1994.

BARDIN, L. Análise de conteúdo. Lisboa: Ed. 70, 1977.

BATISTA-DOS-SANTOS, A. C.; MACEDO, S. T. G. F.; STEPHANY FILHO, L. Tecnologia e psicodinâmica do trabalho: reflexões sobre as vivências de prazer-sofrimento e as estratégias de defesa de 
trabalhadores em processos de implantação de sistemas ERP. In: ENCONTRO DE GESTÃO DE PESSOAS E RELAÇÕES DE TRABALHO - EnGPR, 5., 2015, Salvador. Anais... Salvador:

Associação Nacional de Pós-Graduação e Pesquisa em Administração/ ANPAD, p. 1-16. 2015.

BERNARDO, M. H. Trabalho duro, discurso flexível: uma análise das contradições do toyotismo a partir da vivência de trabalhadores. São Paulo: Expressão Popular. 2009. 192p.

BOLTANSKI, L.; CHIAPELLO, E. O Novo Espírito do Capitalismo. São Paulo: WMF Martins Fontes, 2009.

BOUYER, G. C. Contribuição da psicodinâmica do trabalho para o debate: "o mundo contemporâneo do trabalho e a saúde mental do trabalhador”. Revista Brasileira de Saúde Ocupacional, São Paulo, v. 35 n. 122. p. 249-259, July/De2010.

BAUMAN, Z. Modernidade líquida. Rio de Janeiro: Jorge Zahar., 2001.

BRAVERMAN, H. Trabalho e capital monopolista: a degradação do trabalho no século. XX. 3.ed. Rio de Janeiro: LTR, 1987.

CARRASQUEIRA, F. A.; BARBARINI, N. Psicodinâmica do trabalho: Uma reflexão acerca do sofrimento mental nas organizações. Jornada de Saúde Mental e Psicanálise da PUCPR, Curitiba, v. 5, n. 1, p. 1-19. nov. 2010.

CARVALHO, M. V. B.; GARCIA, F. C. Prazer e sofrimento no trabalho de professores do ensino fundamental e médio: estudo de caso em uma escola estadual da cidade de Curvelo - MG. In: Seminários em Administração FEA-USP: Ensino e Pesquisa em Administração - SEMEAD, 15., 2011, São Paulo. Anais... São Paulo: FEA-USP, p. 1-15. 2011.

CHANDLER, R. O Iongo Adeus. São Paulo: Alfaguara. 1984. CHESNAIS, F. A mundialização do capital. São Paulo: Xamã, 1996. 
CLEGG, S. R.; HARDY, C. Organização e Estudos Organizacionais. In: CLEGG, S. R; HARDY, C.; NORD, W. R. Handbook de Estudos Organizacionais, v. 1. São Paulo: Atlas, p. 1-10. 1998.

DEJOURS, C. Psicodinâmica do trabalho: contribuições da escola Dejouriana à análise da relação prazer, sofrimento trabalho. São Paulo: Atlas, 1994.

DEJOURS, C. A loucura do trabalho: estudo de psicopatologia do trabalho. $5^{\text {a }}$ ed. São Paulo: Cortez, 1992.

DEJOURS, C. Uma nova visão do sofrimento humano nas organizações. In: CHANLAT, J. F. (Org.). 0 indivíduo na organização: dimensões esquecidas. São Paulo: Atlas, 1996. p. 150-173.

DEJOURS, C. A banalização da injustiça social. Rio de Janeiro: FGV, 1999.

DEJOURS, C. Trabalho, Subjetividade e Ação. Revista Produção, Paris - França, v. 14, n. 3, p. 1-10. set./dez. 2004.

DURANTE, D. G.; TEIXEIRA, E. B. Os limites e possibilidades de desenvolvimento humano nas teorias organizacionais.

Desenvolvimento em questão. Unijuí. Ano 6, n. 11. p. 125-151, jan./jun. 2008.

FACAS, E. P. Estratégias de mediação do sofrimento no trabalho automatizado: estudo exploratório com pilotos de trem de metrô do Distrito Federal. 2009 . 115f. Dissertação (Mestrado em Psicologia) . Universidade de Brasília - UNB. Brasília, 2009.

FARIA, J. H. de. Trabalho, tecnologia e sofrimento: as dimensões desprezadas do mundo do trabalho. Revista Crítica Jurídica, México, v. 18. n. 1. p. 197-214. 1992.

FARIA, J. H.; KREMER, A. Reestruturação produtiva e precarização do trabalho: o mundo do trabalho em transformação. Revista Eletrônica de Administração, Curitiba-PR, v. 10, n. 5, p. 1-9. set-out, 2004. 
FLACH, L. et al. Sofrimento psíquico no trabalho contemporâneo: analisando uma revista de negócios. Psicologia e Sociedade, Minas Gerais, v. 21. n. 2. p. 193-202, 2009.

FONSECA, P.J.S; MORAES, R.D. Líder sofre? Subjetividade e sofrimento no trabalho de líderes no pólo industrial de Manaus. Revista Amazônica. Ano 5, v.9, n. 2, p. 69-85, jul/dez. 2012.

FONTENELLE, I. A. Pós-modernidade: trabalho e consumo. São Paulo: Cengage Learning, 2008 (Col. Debates em Administração).

GURGEL, C. R. M. A gerência do pensamento: gestão contemporânea e consciência neoliberal. São Paulo: Cortez,, 2003. $191 \mathrm{p}$.

GHIZONI, L. D. et al. Clínica Psicodinâmica do Trabalho: a prática em diversos contextos de trabalho. Desafios: Revista Interdisciplinar da Universidade Federal do Tocantins, Tocantins. v.1, n.1, p. 74-92, jul/ dez. 2014.

GUIMARÃES JÚNIOR, E .H.; MACÊDO, K. B. Saúde e trabalho do empreendedor: um estudo em psicodinâmica do trabalho. Fragmentos de Cultura, Goiânia, v. 23, n.3, p. 335-347, jul./set. 2013.

LAVNCHICHA, G. R. F. da S. A clínica psicodinâmica: teoria e método. Khóra: Revista Transdisciplinar, [S.I], v. 2. n. 2, p. 1-17. maio, 2015.

MAROCHI, M. L. G. Considerações sobre modelos de produção e a psicologia do trabalho. Revista FAE, Curitiba, v.5, n.1, p.15-28, jan./ abr. 2002.

MARTINS, M. da G. de H. O homem nas abordagens mecanicista da administração e no humanismo de inspiração cristã. Revista Ciências Administrativas, Fortaleza, v. 7, n. 1, p. 1-14, nov. 2001.

MARTINS, S. R.; MENDES, A.M. Espaço coletivo de discussão: a clínica psicodinâmica do trabalho como ação de resistência. Revista Psicologia: Organizações e Trabalho, Florianópolis, v.12, n.2, p. 171184, maio-ago. 2012, 
MENDES, A. M. Aspectos psicodinâmicos da relação homem-trabalho: as contribuições de C. Dejours. Revista Psicologia Ciência e Profissão. Brasília, v. 15, n. 1-3, p. 34-38. 1995.

MENDES, A. M.. Da psicodinâmica à psicopatologia do trabalho. Parte I: Teoria. In: MENDES, A. M. (Org.). Psicodinâmica do trabalho: teoria, método e pesquisas. São Paulo: Casa do Psicólogo, 2007ª p. 27-62.

MENDES, A. M.. Novas formas de organização do trabalho, ação dos trabalhadores e patologias sociais. Parte II: Método. In: MENDES, A. M. (Org.). Psicodinâmica do trabalho: teoria, método e pesquisas. São Paulo: Casa do Psicólogo, 2007b. p. 63-88,

MERLO, A. R. C.; LAPIS, N. L. A saúde e os processos de trabalho no capitalismo: reflexões na interface da psicodinâmica do trabalho e da sociologia do trabalho. Revista Psicologia e Sociedade. [S.I], v. 19. n. 1. p. 61-68. jan/abr. 2007.

MINAYO, M. C. de S. O desafio do conhecimento: pesquisa qualitativa em saúde. 13. ed., São Paulo: Hucitec, 2013.

OHNO, T. O Sistema Toyota de Produção: além da produção em larga escala. Porto Alegre: Artes Médicas, 1997.

RAMOS, A.G. Introdução ao histórico da organização racional do trabalho. Brasília: Conselho Federal de Administração, 2009.

SANTOS, G. B. dos. As estratégias de fuga e enfrentamento frente as adversidades do trabalho docente. Revista Estudos e Pesquisa em Psicologia, Rio de Janeiro, v. 6. n. 1. p. 1-9. 2006.

SENNETT, R. A corrosão do caráter: as consequências pessoais do trabalho no novo capitalismo. 6. ed. Tradução de Marcos Santarrita. Rio de Janeiro: Record, 2002.

TAYLOR, F. W. Princípios da administração científica. 8 ed. São Paulo: Atlas, 2012. 
TRINDADE, F. E. Administração científica de Taylor e as "novas formas" de organização do trabalho: possibilidades de coexistência? Um estudo de caso na indústria têxtil catarinense. 2004, 213f. Dissertação (Mestrado em administração) - Universidade Federal de Santa Catarina, Florianópolis -SC, 2004.

VIEIRA, M. M. F.; CALDAS, M. P. Teora crítica e pós-modernismo: principais alternativas à hegemonia funcionalista. Revista de Administração Eletrônica, São Paulo, v. 46. n. 1. jan/mar, 2006.

Data de Submissão: 10/06/16

Data de Aprovação: 14/09/16 